\title{
Sintren dan Perkembangannya: Studi Kasus Tari Sintren Santri Sanggar Windu Ajibudaya Kaso Tengah Kecamatan Doro Kabupaten Pekalongan Jawa Tengah
}

\author{
Laura Andri R.M. \\ Fakultas Ilmu Budaya, Universitas Diponegoro \\ lauraandrirm@yahoo.co.id
}

\begin{abstract}
Traditional arts or folk art have certain characteristics that lead to the peculiarities of each region. This art emerged as a result of human cultivation to express the value of beauty, pleasure, hope for both himself and others. The existence of socio-culturalreligious experiences in the community gave birth to traditional arts which contained many values of wisdom. Sintren dance that developed in Doro Pekalongan Subdistrict is one of the traditional arts as a result of the aesthetic product of its people. Like other traditional arts, the shift in function and form is also experienced by this Sintren art. By using the Windu Ajibudaya Kaso Tengah Studio as an object of research as well as the use of a qualitative descriptive approach and observation, interview, documentation techniques, it can be seen how the art group's efforts in preserving its artistry. As well as what teachings and symbolic meanings are contained in them.
\end{abstract}

Keywords: Traditional arts, santri sintren, teachings, symbolic meaning.

\section{Intisari}

Kesenian tradisional atau kesenian rakyat memiliki ciri tertentu yang mengarah pada kekhasan masing-masing daerah. Kesenian ini muncul sebagai hasil budidaya manusia untuk menyatakan nilai keindahan, kesenangan, harapan baik untuk diri sendiri maupun orang lain. Adanya pengalaman sosio-kultural-religius dalam masyarakat melahirkan kesenian tradisional yang banyak mengandung nilai kearifan. Tari Sintren yang berkembang di Kecamatan Doro Pekalongan merupakan salah satu kesenian tradisional sebagai hasil produk estetis simbolik masyarakatnya. Seperti kesenian tradisional lainnya, pergeseran fungsi dan bentuk dialami pula oleh kesenian Sintren ini. Dengan menggunakan Sanggar Windu Ajibudaya Kaso Tengah sebagai objek penelitian serta penggunaan pendekatan deskriptif kualitatif dan teknik observasi, wawancara, dokumentasi dapat diketahui bagaimana usaha kelompok seni tersebut dalam melestarikan keseniannnya. Serta ajaran dan makna simbolis apa saja yang terdapat didalamnya.

Kata Kunci : Kesenian tradisional, sintren santri, ajaran, makna simbolis.

\section{Pendahuluan}

Setiap daerah di Indonesia khususnya Jawa Tengah memiliki kesenian tradisional yang berbeda-beda. Kesenian tradisional tersebut mempunyai ciri kedaerahan atau kekhasan masing-masing. Di Pekalongan misalnya, salah satu kabupaten di Jawa Tengah ini terkenal 
dengan kesenian tradisional berupa tari Sintren. Sintren berasal dari kata "sin" yang berarti bentuk dan "tren" yang berarti benda. Sehingga, Sintren dapat diartikan sebagai upaya meninggalkan atau menghentikan segala sesuatu yang bersifat kebendaan.

Tari ini dimainkan oleh beberapa gadis yang masih suci/perawan. Seorang pawang bertugas menjaga penari serta menjadi perantara masuknya roh dalam raga penari tersebut. Sintren dimainkan dengan diiringi tabuhan gending serta beberapa penari pendamping. Tarian yang kental akan unsur mistis ini bersumber dari cerita cinta kasih Sulasih dan Raden Sulandono. Namun Raden Sulandono yang merupakan putra dari Jaka Bahu atau Ki Bahurekso akhirnya menikah dengan Dewi Rantamsari. Keberadaan tari Sintren sendiri difungsikan sebagai alat komunikasi bagi masyarakat pesisir tepatnya Pekalongan.

Seiring berjalannya waktu, fungsi dari tari Sintren mengalami banyak pergeseran dan jarang dilestarikan. Hasil penelitian lapangan yang dilakukan oleh beberapa mahasiswa Sastra Indonesia Undip melalui mata kuliah Kesenian Tradisional yang dilakukan pada bulan Mei 2019 menemukan data bahwa hanya ada beberapa sanggar saja yang masih aktif dan tergerak untuk melestarikan kesenian ini. Sanggar-sanggar tersebut masih tergolong baru dan berdiri dengan sarana prasarana yang belum mumpuni. Salah satu sanggar yang melestarikan tarian Sintren dengan konsep mereka sendiri adalah sanggar Windu Ajibudaya Kaso Tengah. Sanggar ini mengembangkan konsep berdasarkan julukan kota Pekalongan sebagai Kota Santri. Sehingga tari Sintren yang dikembangkan dalam sanggar ini disebut dengan "Tari Sintren Santri", dengan tujuan mengembalikan kesenian tradisional yang merupakan produk budaya nenek moyang yang juga jati diri bangsa kedalam pakemnya.

\section{Metode Penelitian}

Pendekatan deskriptif kualitatif digunakan dalam penelitian Sintren di Pekalongan ini. Karena dengan pendekatan tersebut dapat ditemukan gambaran yang jelas tentang keadaan dan perkembangan tari Sintren sebagaimana adanya. Lokasi penelitian berada di desa Kaso Tengah tempat kelompok kesenian tesebut berada. Metode yang digunakan dalam penelitian ini adalah metode observasi dan wawancara, studi pustaka serta dokumentasi. Observasi dilakukan melalui pengamatan langsung terhadap kesenian Sintren. Hal ini dilakukan untuk mendapatkan gambaran riil terhadap kondisi dan peran kesenian tersebut 
dalam masyarakat. Baik rentetan alur yang dilakukan dalam proses kesenian maupun fungsi Sintren bagi masyarakat pembentuknya. Teknik wawancara dalam penelitian ini menggunakan teknik langsung, yaitu bertemu langsung dengan informan inti yaitu ketua paguyuban Sintren (Gus Eko dan Moh. Luqman) dan beberapa masyarakat sebagai penikmat kesenian. Sementara untuk dokumentasi diperoleh rekaman video tari Sintren mulai dari persiapan, ritual, pementasan serta latihan yang dilakukan sebelum pentas berlangsung. Adapun langkah analisisnya merujuk pada konsep Miles dan Huberman (1994) yaitu melalui proses reduksi data, sajian data dan penarikan simpulan.

\section{Hasil dan Pembahasan}

\section{Eksistensi Sanggar Windu Ajibudaya Kaso Tengah dalam Pelestarian Tarian Sintren}

\section{Sejarah Berdirinya Sanggar Windu Ajibudaya Kaso Tengah}

Sanggar Windu Ajibudaya Kaso Tengah berdiri tanggal 31 Januari 2019. Kelompok kesenian yang eksis melestarikan dan mengembangkan tari Sintren tersebut dipimpin oleh Muhammad Luqman Nugraha serta memiliki guru spiritual bernama Gus Eko Ahmadi dan Nyuwito Bagus Pramudyo. Sanggar Windu Ajibudaya Kaso Tengah beranggotakan 32 orang dengan status pendidikan mulai dari SD sampai Perguruan Tinggi. Selain beberapa yang masih menjadi pelajar, rata-rata anggota lain dalam kesehariannya bekerja sebagai guru dan pendakwah.

Tari Sintren dari sanggar Windhu Ajibudaya Kaso Tengah sebenarnya telah berdiri sejak tahun 2017. Pada saat itu anggota sanggar berkumpul guna membahas penampilan yang akan disuguhkan pada acara peringatan kemerdekaan Indonesia di tahun 2017. Muhammad Luqman Nugraha selaku koordinator, mengajak remaja dan anak-anak Desa Kaso Tengah untuk berlatih bersama Nyuwito Bagus Pramudyo. Akan tetapi pementasan yang dapat dibilang perdana ini, tidak memenuhi ekspektasi dari segi apresiasi masyarakat, sehingga menyebabkan menurunnya gairah dan animo dari para pelaku seni.

Muhammad Luqman Nugraha yang juga sebagai pengurus Lesbumi (Lembaga Seniman Budayawan Muslimin Indonesia) Pekalongan mulai mengamati dan mengobservasi setiap sanggar-sanggar yang berada di bawah naungan Lesbumi Pekalongan. Hal itu dilakukan untuk menemukan peluang mengembalikan semangat dari setiap anggota sanggar Windu Ajibudaya Kaso Tengah. Cara ini rupanya efektif dan berhasil membuat anggota-anggota di sanggarnya termotivasi untuk kembali berlatih 
Sintren. Meskipun usia kelompok kesenian ini masih relatif muda namun memiliki catatan prestasi yang luar biasa, salah satunya adalah menjadi juara 1 dalam kegiatan Jambore Kesenian yang diselenggarakan di Cilacap. Hal ini membawa kebanggaan tersendiri bagi para pemain, terlebih pada saat itu diliput pula oleh tribun Jateng dan NET TV. Semangat mengembangkan Sintren semakin besar dalam diri tiap anggota kelompok kesenian tersebut.

Sanggar Windu Ajibudaya Kaso Tengah baru disahkan pada tanggal 31 Januari 2019 berdasarkan Akta No.19 yang ditulis oleh notaris Setiana Komara, S.H. Sampai saat ini, sanggar tersebut tetap eksis melakukan pementasan. Nama sanggar yang tertera di akta ini adalah sanggar Windu Ajibudaya Kaso Tengah. "Windu Aji” berasal dari nama jalan yang berada di Dukuh Kaso Tengah. Sementara "Kaso Tengah" sendiri merupakan nama salah satu Dukuh di desa Doro, Kecamatan Doro, Kabupaten Pekalongan.

Tarian Sintren yang dikembangkan oleh Sanggar Windu Ajibudaya Kaso Tengah telah dikemas menjadi berbeda dibandingkan tarian Sintren lainnya. Sintren yang selama ini berkembang di masyarakat telah memiliki pergeseran makna. Sintren lebih dikenal sebagai tarian dengan nilai-nilai negatif karena dianggap tidak lagi meneguhkan prinsip "kehormatan wanita" yang dijunjung tinggi dalam inti tari Sintren. Tari Sintren lebih menyuguhkan gerakan-gerakan yang erotis serta mengundang syahwat. Selain itu, terdapat "saweran" selama proses pertunjukannya. Sehingga Lesbumi berusaha mengembalikan ajaran tari tersebut sebagai kesenian dengan nilai yang positif. Dikarenakan Sanggar Windhu Ajibudaya Kaso Tengah merupakan sanggar dibawah naungan Lesbumi, dan Lesbumi merupakan lembaga Islam, maka dilakukanlah modifikasi kembali dari segi presentasi tarian dengan menghilangkan bagian dari pertunjukan yang dianggap negatif, seperti "sawer" dan beberapa gerakan erotis lainnya. Unsur tarian yang dianggap bertentangan kemudian dihilangkan dan diganti dengan unsur baru yang lebih sesuai dengan konsep keislaman. Sehingga hijab dan kebaya yang tidak ketat serta menutup aurat perempuan menjadi kostum baku tari Sintren dari sanggar Windu Ajibudaya Kaso Tengah ini. Konsepnyapun telah bergeser menjadi "tari sintren santri".

2. Gerak, Musik dan Kostum Tari Sintren pada Sanggar Windu Ajibudaya Kaso Tengah

Latihan tari Sintren dilakukan setiap dua kali dalam seminggu, tetapi jika ada undangan untuk melakukan pementasan, ritme latihan menjadi lebih intensif setiap hari di 
satu minggu terakhir sebelum diadakannya pertunjukan. Latihan dimulai pukul 19:00 22:00 WIB di kediaman Muhammad Luqman selaku ketua sanggar, namun kadang latihan juga dilakukan di joglo tempat sekretariat Lesbumi. Para pemain bisa menghafalkan gerakan tarian hanya dalam waktu satu bulan saja, namun untuk mendapatkan gerakan yang lebih luwes para pemain khususnya pesintren membutuhkan waktu lebih lama dengan latihan yang sangat keras.

Makna simbolik pada gerak tari Sintren ada beberapa, yang pertama adalah konsep ketakwaan kepada Tuhan Yang Maha Esa. Hal ini secara simbolik ditunjukkan pada saat gerak sembahan duduk. Gerakan ini memiliki makna rendah diri karena Tuhan adalah Zat yang paling tinggi selain itu diharapkan pertunjukan tari Sintren yang akan dipentaskan dapat berjalan dengan lancar dan membawa berkah bagi seluruh warga dan penonton. Gerakan yang kedua adalah sembahan berdiri yang memiliki simbol penghormatan kepada roh-roh leluhur dan penghormatan kepada para penonton. Dilanjutkan gerakan ketiga yaitu kaki Jengkeng tangan diukel. Gerakan tersebut mempunyai makna simbolik seperti orang yang sedang menanam padi di sawah juga gerakan mengibaskan tangan yang memiliki makna simbolik sebagai gerakan orang menampi beras. Gerak keempat berjingkat dan goyang pinggul pada menyimbolkan rasa gembira seorang anak yang sedang bermain yang diekspresikan lewat gerakan. Saat atraksi pesintren menaiki kurungan menyimbolkan bahwa keberadaan bidadari di langit membantu pesintren melakukan tarian. Gerak terakhir adalah sembahan penutup memiliki simbol permohonan maaf manakala dalam pertunjukkan tari Sintren terdapat kekurangan.

Musik pengiring dalam pementasan antara lain : bonang, rebana, saron, kendang, dan gong. Sementara lagu yang ditembangkan dengan iringan musik pengiring adalah Suwe ora Jати dan Turun Sinten. Kedua lagu ini merupakan mantra yang digunakan dalam kesenian tari Sintren. Tim pemusik harus mengikuti irama lagu dengan benar, karena kesalahan nada yang dimainkan akan mengakibatkan gagalnya pementasan.

Kostum yang digunakan oleh pemain perempuan adalah kebaya dan atasan batik. Sementara bagi anggota Sintren yang berjenis kelamin laki-laki memakai surjan atau lurik lengkap dengan penutup kepala yang disebut blangkon. Untuk pakaian bawahan, penari dan pesintren menggunakan rok dan juga memakai kain sampur (selendang), sementara untuk laki-laki hanya menggunakan celana panjang berwarna hitam. Aksesoris yang 
diperlukan pesintren selain kaos kaki warna kulit juga kacamata hitam dan hiasan bunga melati di atas kepala. Perlengkapan yang bersifat wajib adalah kurungan serta tali tambang yang digunakan untuk mengikat tangan pesintren saat tidak sadarkan diri.

\section{Konsep Ajaran yang Terkandung dalam Tari Sintren}

1. Ajaran tentang Alam Semesta

Tarian Sintren memiliki konsep ajaran alam semesta. Ajaran tersebut disimbolkan melalui perlengkapan pementasan dan sesaji. Dalam perlengkapan, ditunjukkan pada penggunaan bambu sebagai bahan utama pembuatan kurungan serta makanan yang disajikan untuk penonton berupa hasil bumi seperti singkong rebus, ketela rebus, kacangkacangan dan lain-lain. Sedangkan dalam sesaji ditunjukkan pada tumpeng, kopi pahit, air putih, rokok, kemenyan, dan kembang setaman. Semua simbol-simbol tersebut dikumpulkan dengan tujuan agar bisa mensucikan asma (nama) Tuhan dari diri manusia.

Setiap makanan pasti memiliki 4 unsur yaitu tanah, api, air dan angin. Bahan makanan berasal dari tanah, mendapatkan pengolahan dengan menggunakan api, air sebagai penyeimbang, dan angin untuk menetralisir. Melalui simbol-simbol tersebut ajaran yang ingin disampaikan adalah manusia harus menghargai apa yang diberikan oleh alam. Rasa menghargai alam ini terwujud dengan cara bersyukur kepada Tuhan yang telah memberikan atau menciptakan alamnya untuk manusia. Bahwasanya, setiap makhluk hidup tidak akan bisa bertahan tanpa adanya keempat unsur baik tanah, air, api maupun angin. (hasil wawancara dengan Gus Eko, pimpinan Lesbumi Pekalongan, 5 Mei 2019).

2. Ajaran tentang Manusia

Ajaran tentang manusia yang ingin disampaikan dalam tari Sintren adalah ajaran penghapusan "Pancamakara" atau Mo-Limo, yang ada dalam aliran kepercayaan Tantrayana. Masih banyak perdebatan mengenai bagaimana konsep dari Tantrayana ini, bahkan beberapa menganggap aliran ini merupakan aliran "menyimpang" dan beberapa lebih nyaman menyebutnya sebagai anti-mainstream. Diketahui bahwasanya bumi Nusantara pada kisaran abad 8-14 M sangat dipengaruhi oleh budaya Hinduisme dan Budhisme, padahal apabila ditelaah lebih jauh kedua konsep fundamental ajaran ini sangat bertolak belakang. Budhisme merupakan bentuk protes dari implementasi sistem religi Hindu dalam hierarki sosial masyarakat Nusantara klasik dalam bentuk sistem kasta. 
Tantrayana sendiri muncul dan berkembang pada masa keemasan Majapahit, dimana terjadi sinkretisme antara Hindu-Buddha disebut dengan Siwa-Buddha Tatwa. Latar belakang munculnya fenomena tersebut adalah adanya kebijakan politik dari raja Hayam Wuruk yang menganut dua sistem religi ini. Selain itu ada faktor lain yang jauh lebih penting yakni korelasi spiritualitas Tantra. Konsep dasar dari Tantra, yakni lebih menekankan harmoni dan juga peribadahan melalui meditasi mantra serta mistisisme, dengan menempatkan manusia sebagai wadah suci untuk mencapai pencerahan. Manusia adalah cerminan mikrokosmik kekuatan alam semesta, dengan mengedepankan segala bentuk praktik yang memaksimalkan tubuh dan bersifat duniawi untuk mencapai pembebasan atau moksa (Dewi,2013:1-2).

Ajaran Tantra lebih berfokus pada pemujaan terhadap Shakti (aspek feminim dari dewa, terutama dewa Siwa). Praktiknya menekankan pada keutuhan yang dicapai dalam aspek feminim dan maskulin dalam simbol Shiva dan Shakti. Salah satu contoh teknik dari Tantra adalah Panca Makara, atau disiplin meditasi dan konsumsi seperti; madira (anggur), matsya (ikan), mamsa (daging), mudra (gerakan tangan), dan maithuna (hubungan seksual). Diantara kelima makara tersebut,disiplin dalam hubungan seksual dianggap penting dan kompleks, karena terdapat transformasi paradigma dari relasi seksual yang dianggap rendah/profan menjadi relasi suci, dengan syarat mampu mengalihkan energi yang awalnya berlandaskan nafsu dan cenderung negatif, menjadi rasa cinta kosmis yang menyebar dan meliputi seluruh alam semesta (Dewi, $2013: 3$ ).

Disinilah peran daripada tari Sintren, yakni menghapuskan ajaran yang dianggap melenceng jauh dari konsep ajaran setelah Hindu-Buddha, yakni Islam, yang semula berpusat di Jawa Timur kini telah sampai ke Doro, karena sebagian masyarakat sudah tidak lagi bisa menerima praktik Panca Makara, maka muncullah tari Sintren. Ditinjau dari makna atau arti, kata "Sin" berarti bentuk, dan "Tren" yang berarti benda, sehingga Sintren dapat ditafsirkan sebagai tindakan meninggalkan atau menghentikan segala sesuatu yang bersifat kebendaan. Tari Sintren apabila dirunut dari cerita lisan yang tersebar secara turun temurun, pertama kali muncul akibat Sulandono dan Sulasih yang hubungannya tidak direstui ayah dari Sulandono yaitu Jaka Bahu atau Bahurekso, yang merupakan anak dari Ki Ageng Cempaluk tangan kanan dari Raja Mataram Islam. Sehingga muncul bentuk penanaman paham baru dengan memadukan atau menyisipkan kebudayaan lokal dengan 
dasar ajaran Islam guna menggantikan kebudayaan sebelumnya tanpa adanya konflik, semacam mendapatkan kekuasaan secara de facto tanpa adanya represi.

3. Ajaran tentang Budi Luhur

Berikut adalah beberapa makna ajaran yang berkaitan dengan sikap budi luhur;

a. Seorang perempuan harus bisa menjaga kehormatan dan kesuciannya. Ia juga tidak boleh mencintai lawan jenis secara berlebihan serta tidak sembarangan menyerahkan dirinya kepada lelaki. Perempuan harus bisa menjunjung tinggi nama baik dan kehormatan keluarganya, jujur dalam segala perbuatan yang dilakukan dan perkataan yang diucapkan.

b. Ajaran luhur mengenai bela tanah air, didalam tari Sintren terdapat properti berupa "kacamata" hitam, yang diibaratkan sebagai orang yang buta. Sintren yang terbelenggu menggambarkan bangsa Indonesia yang waktu itu terbelenggu oleh penjajah. Setelah menyaksikan pementasan tari Sintren diharapkan penonton memiliki semangat juang untuk melepaskan diri dari belenggu penjajah. Selain itu ikatan tali yang mengikat tangan pesintren sesaat sebelum dimasukkan dalam kurungan kemudian keluar dengan ikatan yang sudah terlepas memberikan gambaran filosofis bahwa setiap belenggu yang mengikat kebebasan gerak manusia mesti dilenyapkan dari bumi yang merdeka agar tidak ada lagi bentuk penjajahan di muka bumi.

c. Puasa mutih yang dilakukan pesintren memiliki makna ajaran yang berupa tugas dan kewajiban manusia terhadap Tuhannya.

d. Sesaji berupa kembang setaman dan makanan yang disajikan untuk penonton yang berasal dari hasil bumi memiliki makna ajaran berupa kewajiban manusia kepada alam.

\section{Makna Spiritual yang Terkandung dalam Tari Sintren}

1. Doa dan Mantra

Tari Sintren yang dilestarikan oleh Sanggar Windu Ajibudaya Kaso Tengah sebenarnya memiliki doa dan mantra khusus yang dibacakan oleh pawang saat pertunjukan dilangsungkan. Namun Muhammad Luqman Nugroho (ketua sanggar sekaligus pawang) tidak bisa membeberkan doa dan mantra kepada orang lain yang tidak berkepentingan. Tentu saja karena mantra dan doa merupakan sesuatu yang sakral dan hanya boleh 
diketahui oleh guru spiritual dan pawangnya saja. Pawang hanya memberikan informasi bahwa untuk dapat kerasukan seorang pesintren harus tetap fokus kepada ketukan gendhing yang mengiringi. Lagu Turun Sintren adalah salah satu sarana yang bisa disebut dengan mantra untuk memanggil bidadari yang nantinya akan merasuki tubuh pesintren.

\section{Lirik Turun Sintren}

\section{Turun-turun sintren \\ Sintrene widadari \\ Nemu kembang yun ayunan \\ Nemu kembang yun ayunan \\ Kembange Putri Mahendra \\ Widadari termuruna \\ Sulasih Sulandana \\ Menyangkuti ragane sukma \\ Ana sukma saking surga \\ Widadari temuruna}

Lirik ini kemudian akan terus diulang dengan tempo yang sama guna memudahkan penari sintren memasuki fase trance atau kerasukan. Gus Eko Ahmadi selaku guru spiritual menjelaskan bahwa mantra dan doa yang dibacakan oleh pawang adalah sholawat. Namun dari sumber yang diperoleh melalui studi pustaka, ditemukan bahwa ada doa khusus pada setiap pertunjukan tari Sintren yang disimbolkan sebagai sikap ketaatan dan perlindungan yang ditujukan kepada Allah dalam agama Islam lewat sarana bidadari yang dianggap sebagai dewi Rantamsari yang mengindangi atau merasuki penari sintren. Simbol ketaqwaan ini diwujudkan dalam doa "Aji Jaya Mantra."

"Bismillahirohma'nirohim. Sedulur papat lima pancer kakang kawah adi ari-ari rohe si jabang bayi sisihaken sawentara saka raganing arep nggo dolanan dilindungi ratu Ayu Gadung lung ajungan Dewi Ayu Rantamsari saksine indang dayang bahu rekso tanah kene."

Terjemahan :

Bimillahirohma'nirohim. Saudara empat lima pusar kakak kawah adik ari-ari rohnya si jabang bayi disingkirkan sementara dari raga untuk dilindungi ratu Ayu Gadung Iung tempat Dewi Ayu Rantamsari yang menjadi saksi penghuni dayang tanah sini.

Doa “Aji Jaya Mantra" menggunakan kalimat Bismillahirohma'nirohim dalam agama Islam untuk mengawali semua kegiatan agar berjalan lancar dan yang ditujukan kepada Dewi Rantamsari dalam doa tersebut yang berbunyi “... arep nggo dolanan dilindungi ratu Ayu Gadung Iung Anjungan Dewi Ayu Rantamsari saksine indang dayang bahu”, (Darmoko,2013 :98). 


\section{Ritual dan Maknanya}

Ritual yang biasanya dilakukan oleh penari Sintren adalah puasa mutih selama tujuh hari. Sebenarnya puasa ini harus dilakukan selama 40 hari berturut-turut, namun hal ini tidak dilakukan lagi karena terkesan memberatkan. Puasa mutih biasa dilakukan hanya dengan makan nasi tanpa lauk, singkong rebus, tahu rebus, dan tempe rebus serta hanya meminum air putih atau tanpa rasa dan warna.

Pembakaran kemenyan di awal pertunjukan merupakan syarat pemanggilan roh atau bidadari dalam tari Sintren. Pembakaran ini dilakukan dengan harapan memanggil Dewi Rantamsari agar masuk ke dalam raga penari. Setelah itu, digunakan tali yang diikatkan pada kedua tangan, yang merupakan perlambangan dari sebuah ikatan erat yang menyatukan antara penari Sintren dengan bidadari atau roh yang masuk ke dalam tubuh pesintren. Ada pantangan yang tidak boleh dilanggar yaitu para pemain tidak diperbolehkan berlatih tarian Sintren di luar daerah Pekalongan. Namun sayangnya tidak ada penjelasan konkrit megenai alasan dari pantangan tersebut.

\section{Sesaji dan Maknanya}

Dalam sistem sosial budaya masyarakat Jawa yang cenderung agraris-tradisional, kegiatan upacara menjadi bagian yang tidak terpisahkan dalam kehidupan. Dalam kesenian Sintren, perilaku riil ditunjukkan dengan pembuatan sesaji (sajen). Masyarakat Kecamatan Doro merefleksikan kegiatan upacara sesaji pada kesenian Sintren, sebagai berikut:

a) Tumpeng alus berbentuk kerucut, melambangkan rasa syukur dan permohonan kepada Tuhan Yang Maha Esa agar masyarakat Kecamatan Doro diluruskan permohonannya dan dijauhkan dari segala godaan.

b) Lauk-pauk yang berjumlah tujuh buah yang sudah dipincuk dibungkus daun pisang, melambangkan arti pitulungan atau pertolongan dan kesederhanaan.

c) Tujuh macam jajanan pasar, mempunyai arti agar masyarakat Kecamatan Doro tetap merakyat dan sederhana.

d) Tujuh macam buah, menunjukkan arti pitulungan dan buah-buahan sebagai perlambang agar tidak hanya hasil padi saja yang berlimpah namun juga hasil kebun yang lain.

e) Macam-macam air yang berupa kopi, teh, air putih dan wedang jahe menyimbolkan masyarakat Kecamatan Doro mendapat irigasi yang mudah untuk bertani. 
f) Kembang telon (kembang tiga rupa) yang terdiri dari bunga mawar merah dan mawar putih, bunga kenanga, bunga kanthil sebagai sarana pemanggil Dewi Rantamsari.

g) Tujuh buah nasi ponggol atau nasi golongan. Nasi putih yang dibentuk bulat memiliki simbol kebulatan tekad menjadi satu seperti rasa gotong royong masyarakat Kecamatan Doro.

\section{Simpulan}

Tari Sintren hadir sebagai ajaran yang bertujuan menghilangkan adat dan kebudayaan pada masa atau periode sebelumnya dimana konsepsi Tantrayana dan praktik Panca Makara masih mendominasi dan sangat bertentangan dengan nilai dan norma masyarakat Doro, Kabupaten Pekalongan. Sanggar Windu Ajibudaya Kaso Tengah telah berhasil memodifikasi bentuk tarian berdasarkan konsep keislaman menjadi "tari sintren santri" dengan tujuan mengembalikan tari Sintren ke bentuk aslinya. Selain itu kesenian ini juga digunakan sebagai alat penyadaran bagi masyarakat terhadap perilaku-perilaku menyimpang yang bertentangan dengan ajaran agama. Ajaran tentang ketakwaan terhadap Tuhan Yang Maha Esa, ajaran tentang alam semesta dan ajaran tentang sikap budi luhur menjadi bagian inti yang ingin disampaikan tari Sintren Sanggar Windu Ajibudaya Kaso Tengah kepada masyarakat penikmatnya. Semoga tari Sintren makin melestari dan berhasil menjadi sarana komunikasi positif bagi masyarakat.

\section{Daftar Pustaka}

Ayasy, Yahya, dkk. 2019. "Sanggar Windu Ajibudaya Kaso Tengah: Tarian Sintren Santri dari Kecamatan Doro, Kabupaten Pekalongan.” Makalah dan wawancara Pribadi Mata Kuliah Kesenian Tradisional Sastra Indonesia FIB Undip, 15 Mei 2019.

Darmoko, Dwi Puji. 2013. "Dekonstruksi Makna Simbolik Kesenian Sintren (Studi Kasus pada Paguyuban Sintren Selamet Rahayu Dusun Sirau, Kelurahan Padiraksa, Kecamatan Pemalang, Kabupaten Pemalang." Tesis Universitas Sebelas Maret. https://digilib.UNS.ac.id (diakses pada 11 Mei 2019).

Dewi, Saras. 2013. Budaya Erotika Timur. Serial Kuliah Umum Seksualitas Nusantara. www.suarakita.org. diakses tanggal 22 Juni 2019.

Miles, M.B, Huberman, A.M, (1994). Qualitative data analysis, 2nd ed. USA: Sage Publication. 